UC-28

Reporting Date: July 1975

Iscued: Folruary 1976

\title{
A General Ion-Optical Correction Element
}

by

H. D. Ferguson

J. E. Spencer

Klaus Halbach"

"Lawrence Berkeley Laboratory, University of California, Berkeley, CA 94720.

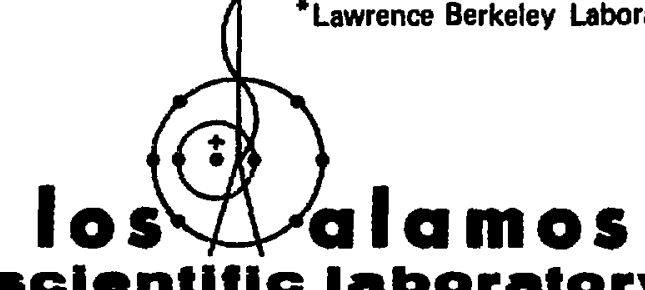

selentiste laboratory

of the University of California

los alamos, NeW mexico 87545

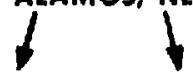

An Altirmative Action/Equal Opportunity Employer 
Printed in the United Stutes of America. Amilable from National Technical Informution Service

U.S. Depurtment of Commerce

5285 Part Royal Roud

Speinglold, VA 22151

Price: Printed Copy \$4.50 Microfiche \$2.25

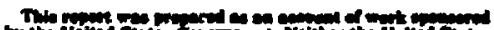

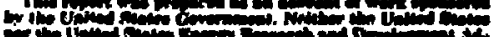

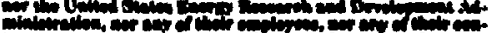

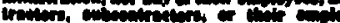

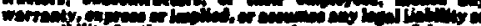

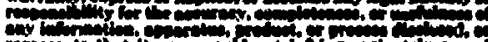

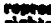


A GENERAL. ION-OMTICAL COAMI!CTION ILGHANT

by

11. D. Perguson, J. I:, Speneer, and Klaus Inlbach

\title{
ANSTMACT
}

\begin{abstract}
A general purpose type of wultipole megnet is described which provides sone unique advanesgos. It produces a very uniform dipole field which can he rotated about the iongitudinal axis of the wagnet. Higher order multipoles can also be rotated and can he excited simultaneousily without the use of independent coils. A mognet having octupole geowetry was huife and shown to verify the basic ideas.
\end{abstract}

\section{INTROAMLTION}

Host heas line systems consint of combinttions: of dipoles, quadrugoles, and accastinatly higher order multipoles, arranged to provide a desired ojt icat performance. Megardless of the specticic application. it is often useful to make small changes in the systen either to correct simall errors and atsalignments, to tunc il or make weasurements on it that reveat its optical proflerties, or passibly to aitch ifs optics to a particular experiment or other comparable iystom. The ouletpurpose mag. nets described here fill these roles. Twn such magnets have licen fol operat fon in the tos Mamos Neson Physics Facility (LAHP) switchy-rd simee the spring of 1973 ant cin be used. depending on tha hussing arrangenent, to produce cither a dipole field of arbitrary orientation, a quadrupole field of arbitrary orientation, or an octumele field with all orientation determined by the physteal orientation of the magnet.

Benaroya and Mamler' developed a mignet supablot of producing a dipote field with arlsitrary oriensation by using two sets of coils arranged in a 2.4 fole circular stecl structure. The coils were atr. ranged to provide cost-and sintlike current distributions to give the two arthogonal ficld somplsments. Qualititively, the same result cin be achicved with a design that represents another extreme--nascly, two sets of coils of the window-frase type in a square steel frame. When one atceupts to design a keneral-purpose wagnet, it is cleur that a Iarge range and varfety of characteristics have to he considered, such we the type. strength, and qualizy of ficlds to he produced; the stze and complexity of the sceel and cotl configuraRions: and the bussing, power supplies, and control armangesents. We love concluded that an octupole configurat ion is a good compremtse solution whenever it is necessiry to produce hoth dipole and quadrupote ficlis. Hepending on the intended usc. 12-pole magnet wight he a hetecr thoice. If one also wants to produce sextupale fields with arbitrary orientarinn.

Aceatse the rule "to produce a $34-p o l e$ field. excite the poles like sinkï or coski" would appear to lue too crude in the ease of an oetupole, we dis. cuss ill detill the proper exciration and expected ficlu yuality in the next section. The specifie design details of the iron/ceil configuration and the fussimg and poser stuply setuy are discussed in soc. 111: results for tlac prototghe oftupule system are diccusised and compared $k$ ith the theorctical expettat inus in Ses. II.

\section{HII:011}

since we are jrimarily concerned here with the ficlds in the region araund the opticel axis of the manuet, or with the line integrals of these fields 
taken through the apnet (Including the fringe fields), we need so consider cnly two-dimensional rlelds. The discussion of harmontes in muleipole magnets is glven in Ref. 2, and we use the rewules of that treateont, with wodifications in notation only.

Magner lc flelds in a vacues that have compononts only in the $x-y$ plane and do not depend on the third space coordinate can convóntenty be derived from either scalar potential $v$ or a vector potent bal that needs zo have only a compunthe $A$ in the direct. ion perpendicular to the $x-y$ plane. Inspection of the aaristostatic equations shows that $A$ and $v$ are harmonically conjugate. or wore specifically, that the function

$$
F(z)=A(x, y)+N(x, y)
$$

is an ansigte function of the complex variable $z x$ * iy $=$ re $^{\text {lo }}$. The magnetic field components $"{ }_{x}$ and $/ y$ are abtained frow 1 shrough

$$
H \cdot \|_{x}-i H_{y} \cdot 1 d a / d=.
$$

whore $H^{*}$ Is the complex conjugate of 11 .

It is converient to axpand $f$ in a Iayjor series

$$
F(s)=\sum_{n=1}^{\infty} c_{n}\left(z / r_{0}\right)^{n} \text {. }
$$

where $r_{0}$ Is a normaliastion length to be spocified below and the $c_{n}$ are the wutelpole coefficients. In s perfect mule ipole angnes, the sum in fily. (3) has only one serm.

A sealar potential surface, which can represent - pale contour. would then be obtained by secting the lesglnstry part of $f$ zqual to constant. If ve talk spacifically about the pole of an ideal octupole that intersects the $x$-axis at $x=r_{0}($ lith. 1$)$, its contour will be given hy

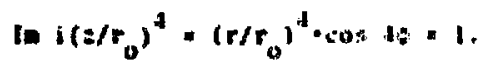

If only this one pole ix oxcited hy to sempre turns. the coefficlents $c_{n}$ are purcly imaghonry and proportional to $v_{0}$, thas is. in thas the forts

$$
c_{n} \cdot i v_{0} j_{n}
$$

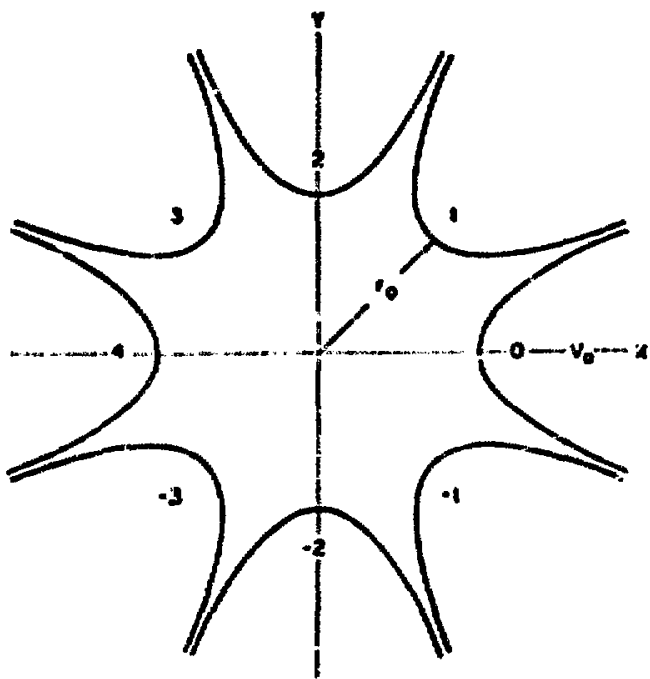

Hit. 1. Roference geonetry, pole deslgnation, and exclitation pattern for Table I.

weh " $n$ heing real and independent of $v_{0}$. The expresston for the fields then gakes the form

$$
i * \frac{v_{0}}{r_{a}} \leq h_{n}\left(t / r_{0}\right)^{n-1} \text {. }
$$

with

$$
h_{n} \cdot n l_{n} *
$$

In Table IIl of Ref. 2, the values of $n f^{\prime 4}$ are then for an latal octupole for $n=1-34$ and are zepre. duced here in Table $I$ up to $n$. 16 after multiplics. tion by + to atve $h_{n}$. we can say the followint about the miacrical values cabulated for the $h_{n}$.

1. The fact that $h_{n} \cdot 0$ when $n$ is in suan cultiple of forr is a consequence of symatry and not pole conkour.

2. $h_{n}$ - a for odd aultiples of four ho srut only for ldeal nole shapes and will nol hold if one devidics from the ideal contour (Fq. (A) in a stenificant way.

5. The values of $h_{n}$ for all orher $n$ do nos depend very strangly on the pole shape for seall values of $n(n \$ 10)$.

lrepending on the excltation partern one uses, harmonics whith would be present for single-pole cxefratlon (Table $n$ wey not he present for ressons of symetry regardless of cocficiciens magnitude. This will hecome clearer in the suctecding discusston. 
TABIE I

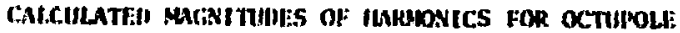
AND DUOUICAYOLE MACINITS FROY REF, 2

\begin{tabular}{|c|c|c|}
\hline In. & $h_{\Omega}(N-4)$ & $h_{n}(n=6)$ \\
\hline ! & $\begin{array}{l}0.220 \\
0.399\end{array}$ & $\begin{array}{l}0.158 \\
0.293\end{array}$ \\
\hline $\mathbf{5}$ & 0.492 & 0,399 \\
\hline 1 & 0.5011 & 0.460 \\
\hline 5 & 0.436 & 0.503 \\
\hline 6 & 0.31 .3 & 0.500 \\
\hline 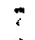 & 0.160 & 0.464 \\
\hline 3 & $n$ & 0.400 \\
\hline 9 & $-3.54:-2$ & 0.313 \\
\hline 111 & $-4.12 \quad 1:-2$ & 0.213 \\
\hline 11 & $\underset{n}{-2.52} \mathrm{n}-2$ & 0. 106 \\
\hline 1.5 & $\begin{array}{ll}2.24 & 1:-2 \\
3.22 & 1:-2\end{array}$ & $\begin{array}{l}-2.72 \mathrm{l}:-2 \\
-1.113 \mathrm{l}:-2\end{array}$ \\
\hline $\begin{array}{l}15 \\
16\end{array}$ & $2 .+60$ l:- 2 & $-1 .: 31:-2$ \\
\hline & & \\
\hline
\end{tabular}

Annther result from Rot. I is the expression for the fleld when a pole is at an angular Jncation $x_{m}=(\pi / 4)$ and is exciend hy $v_{m}$.

$$
u^{*}=-\frac{r_{n}}{r_{a}} n_{n} \cdot e^{-i n m(n / 4)} \cdot\left(=/ r_{0}\right)^{n+l} .
$$

when the actupolo whown in Fig. I is excited

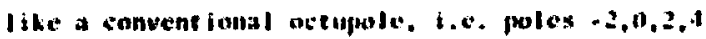
are exclted with et, anflere turns, and poles $-5,-1$. 1,3 are excited with $-t_{0}$, application of lial. 171 shows that the only harmunics that an he unzero

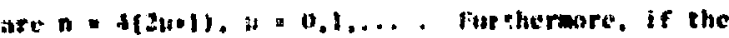

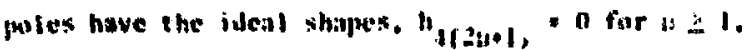
the resule ing fintal is thot of an ident octumole.

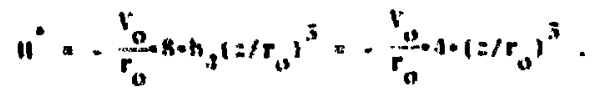

If the pole contout deviates significantly from the one given by fic. (t). the odt milejples of four way afprear whth substantial strength. flowever, if one intends to use only a fraction of the apereure, the lowest allowed hareanis, $n=12$, is cue down in amplitude relative to $n=t$ hy $\left(r / r_{0}\right)^{8}$ from whit it would be at full sperture, mish ing it sencrilly ateceptable for use as a corrective dement.
The excitacton of the octupole shown in Fig. I required to produce a quadrupole field oriented such that $\|_{y}=0$ on the $x$-axts is ohtained hy exciting poles 0 and 4 with $v_{0}$, and poles 2 and -2 with $-v_{0}$ Application of liq. (7) shows that the only allowed harmonics are $n=2(2 \mu+1)$, so that one gets

$$
\|=-\frac{v_{0}}{r_{0}} \cdot 4 \cdot \sum_{11 \pi_{0}} h_{2(2 \mu+1)}\left(z / r_{0}\right)^{4 \mu+1} .
$$

The coefficients in Table I are, of course, only a rough approximation if the pole shape is as differend from the ideal one as is the sase for the prototype pole contour shown in fig. 2 . In cases whaze one cannot allow strong higher harmonics, such as the duodecapole, one has no other choice but to increase the magnet apertiure. As outlined ubove. changing the pole contour would have little effect in $h_{6}$

If one wants to produce a quadrupole field oriented so that $\|_{x}=0$ on the $x$-axis, one excites poles -1 and 3 with $v_{0}$, and -3 and $i$ with $-v_{0}$, and the field is descrihed by the right side of Eq. (9) multiplied lyy i. Arbitrary orientat ton of the quadruphele ficld axes is then achicved by wixing these two nodos of excitation. If the first mode of excitution has a strength. $V_{0}$ cosn, and the second, $v_{a}$ ina, then the effective angular rotation (9) of the axes of the resulting quadrupole relative to those induced by the first wole of excitation will be $=a / 2$

To prouce a dipola field oriented such that $\| y$. O on the $x$-axis. poles 2 and -2 (Fig. I) should not be excited. Furthermore, it is clear that if

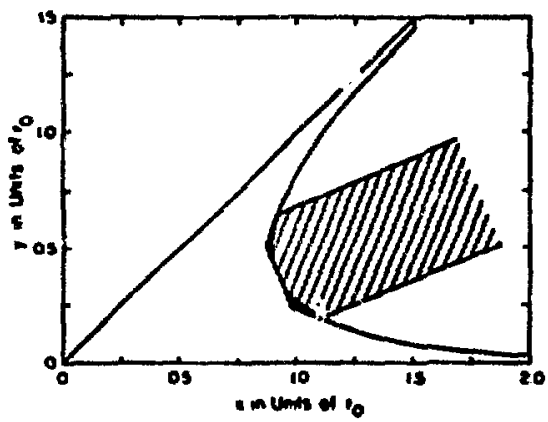

Pig. 2. Comparison of pole contour uxed for the mugnet shown in Figs. I and 4 with the isleal octungle contour derived in the tex:. 
one excites pole 0 with $v_{0}$, pole 4 should be excited with $-V_{n}$. Similarly, the excitation of pole -1 should be the same as the excjtation of pole 1 , whereas poies 3 and -3 must have the sawe manitude of excitation as poles 1 and -1 , but opposite sign. Finally, to sake the field as uniform as possible, the agnitude of excitation of poles 1 and -1 relative to $v_{0}$ can be used to cancel the contributions from the next-higher allowed harmonic, $n=3$. It is easy to see that this can be accomplished if poles 1 and -1 are excited by $v_{0} / \sqrt{2}$. Using Eq. (7), to superimpose the contributions frow the individual poles excited in this pattern, shows that the contributions to $n=5$ also cancel, so that one obtains

$H=-\frac{v_{0}}{r_{0}} 4 \cdot \sum h_{n}\left(2 / r_{0}\right)^{n \cdot 1} ; n=1,7,9,15,17, \ldots$.

Again, the coefficients $h_{n}$ are only a rough guide to the strength of the nultipoles which actually occur. Furthermore, the cancellation of multipoles has nothing to do with the specific magnitudes of these coefficients, but depends only on symetry and excitation pattern.

To produce a dipole field oriented with $\|_{x}=0$ on the $x$-axis, one uses the sane excitation pattern as above, but rotated by $90^{\circ}$. Superposition of these two excitations can then give a dipola field at an arbitrary orientation.

If one wants field patern not oriented along the $x$-axis (the $\phi \pm 22.5^{\circ}$ line going symetrically between two adjacent poles, one simply superiaposes the excitation pattern that gives In. (10) with the same patern rotated by $45^{\circ}$. This means that poles 0 and 1 should he excited with $v_{0}(1+\sqrt{0.5})$, poles -1 and 2 should be cacited with $v_{0} \sqrt{0.5}$, and the renaining poles with the corresponding negative values. The ficld is obtained by multiplying the various terms in the $\operatorname{sum}$ in E.Y. (10) by

$$
1+e^{-i n \frac{\pi}{4}}=2 \cdot \cos n \frac{\pi}{8} \cdot e^{-i(n-1) \frac{\pi}{8}} e^{-i \frac{\pi}{8}} .
$$

\section{yiclding}

$I^{*}=-\frac{v_{0}}{r_{0}} \cdot 4 \sqrt{2+\sqrt{2}} \cdot c^{-i \frac{\pi}{8}} \quad \because h_{n} \cdot \frac{2 \cos (n \pi / 8)}{\sqrt{2}+\sqrt{2}} \cdot\left(2 e^{-i \frac{\pi}{8} / r_{0}}\right)^{n-1}$,

$$
n=1,7,9,15,17, \ldots .
$$

For $n=1,7, y, 15,17, \ldots, 2 \cos (n / 8) / \sqrt{2+\sqrt{2}}=1,-1,-1$. $1,1, \ldots$, that is, the magnitudes of the harmonics, relative to $n=1$, are unchanged, only the signs are reversed for $n=7,9,23,25, \ldots$. To produce the sawe dipole field strength, the second pattern requires 1.082 times the anpere turns of the first pattern.

We point out that such a magnet can be used to produce all of the above fields simultaneously, i.e., dipole, quadrupole, and octupole, provided one arranges the colls and power supplies appropriately. This feature, together with the ability to rotate the dipole and quadrupolc fields, makes the magnet quite versatile. The actual field uniformity achievable for the dipole field using the technique described above should be quite good, especially compared to more conventional magnets, as we show in a later section. If for some reason one needs to use a larger fracticn of the aperture than is compatible with a required field uniformity, it might be preferable to adopt a 12-pole design. We leave it as an exercise to the readers to convince themselves that the following characteristics are achievable with this kind of magnet.

1. A rotatable dipole field which has only the harmonics $n=1,11,13,23, \ldots$.

2. A rotatable quadrupole field which has only the hasmonics $n=2,10,14,22 \ldots$.

3. A rotatable sextupole field which has only the harmonics $n=3,9,15, \ldots$ and

4. Any linear combination of the above.

\section{OCTUPCLE DESCRIPTION}

The system which was built has an octupole geometry as shown in Figs. 3 and 4 . For reasonably small currents ( $i \leq 200 \mathrm{~A}$ ), we have found it best to excite the different poles using a single, unregulated bipolar powez supply connected to a bank of independent regulators shown schematically in Fig. 5 . Then, depending on the numher of regulators as well as the bussing arrangement adopted, it is possible to produce difole, puadrupole, and octupole fields. For instince, if only four regulators are used they should drive the four pairs of opposing poles with a bussing arrangenent which allows reversing the relative polarity hetween individual pole pairs. Depending ou the huss connection, one can then obtain 


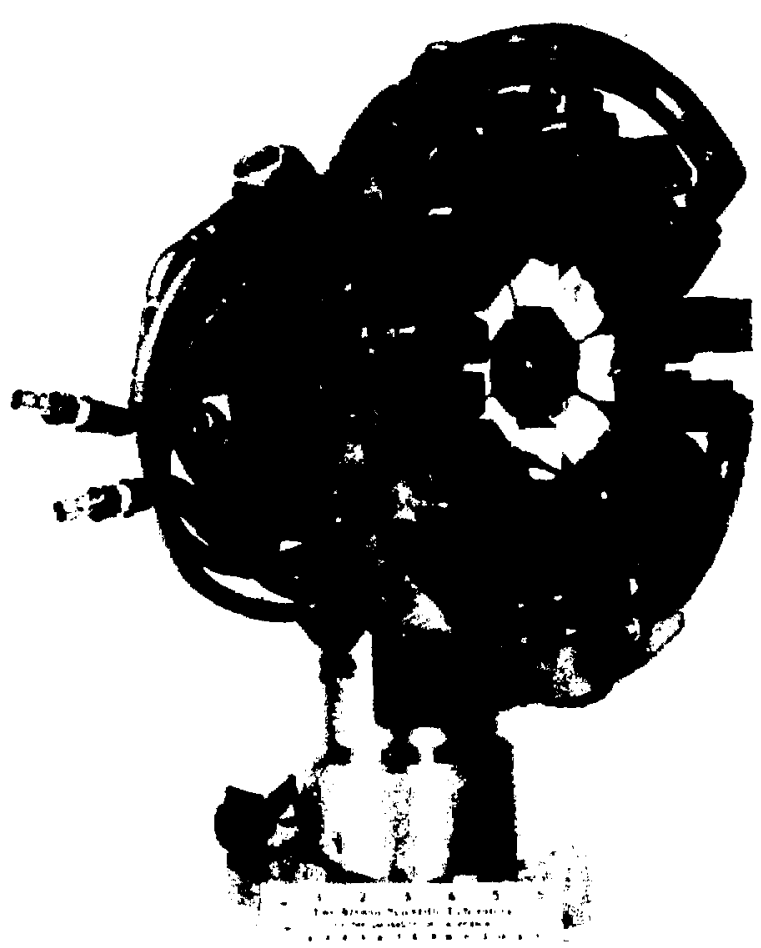

Fig. 3. One of the octupole steerine nagnets designed for tuning a bean at LAPF. The gap opening is 5.26 co to accomodate a 5.08-cm beal pipe. Magnet fits into $<30$ co space lone the bean line and delivers a dipole field Integral of $>25 \mathrm{kr}-\mathrm{em}$ with a deviation from uniformity $< \pm 10^{-4}$ over the central quarter of its aperture.

either a dipole or quadrupole and octupole field. however, if one requires only a rotatable dipole field, then just two independent regulators are required; and if all multipole fields are required simultaneously, a total of eight independent regulators is necessary.

In the angnet shown in Figs. 3 and 4 , opposing pairs of poles were excited together so that only four requlators per mgnet were used. Buss bars were provided between each pair of opposing poles so that the relacive magnetic polarity could be easily reversed for each pair by shifting the buss bar on its switching assembly (Fig. 3). The buss bors were fabricated from comercial quality copper, and the insulation coaponents were fabricated frow paper base phenolic and permali rods and nuts.

Magnet pole pieces were fabricated from Arnco ingot iron, rough machined to size, and subsequently stress relieved before final machining. It was

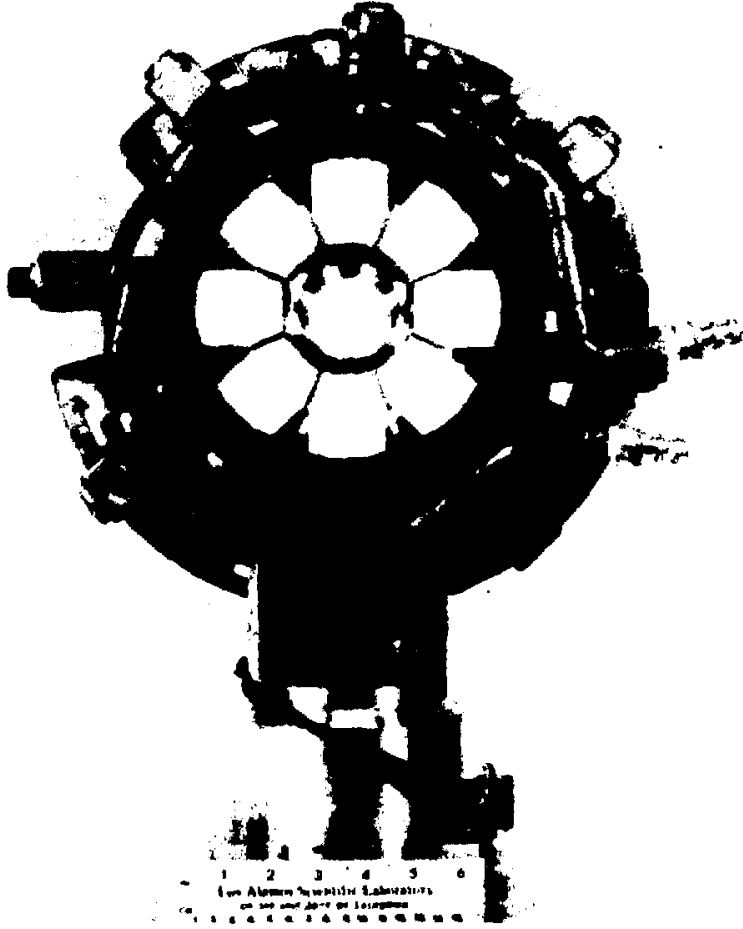

Fiz. 4. Viow of megnet along the bas direction. Pottine opoxy for the coils we losded with aluin fouder to inprove its proparties in high-radiation fields. Alvinu ring near the bea plpe pariphery mintains fixed coll positions.

hoped that the Armco poles would reduce the effects of residual fields at zexo excitation. The pole contour used is show in Fig. 2, where it is compared to that for an idesl octupole. For the S.28cm bore shown in the figures, the contour is 0.25 cm by $45^{\circ}$ champfer on $1.27-\mathrm{cm}$ pole width. With these dimensions, we atteapted to approximate the ideal contour in an integral sense in the region nearest the center of the magnet. This might have been done better by using a wider pole, but the iron for tiis was not readily available. Geometrical constraints from coil allocation often outweigh the importance of weching the theoretical pole contour as indicated in the previous section. We should point out, however, that considerable attention was given to what the highest fields in the iron were likely to be using these dimensions. The ends of the poles, at entrance and exit, were achined to a radius to simplify coil winding and their axial lengths were wads as long as possible compured to the bore radius to minimize end effects. 


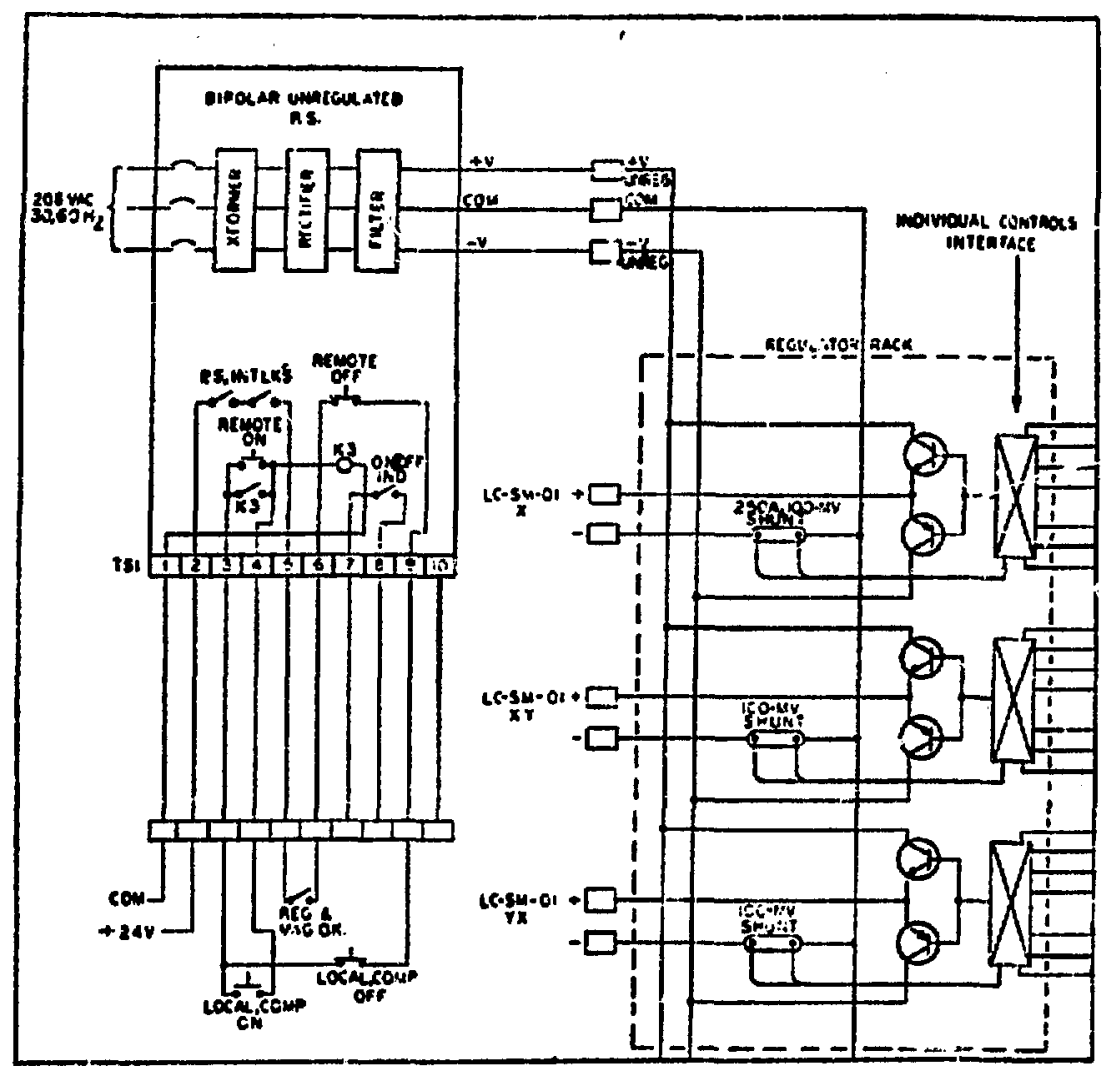

Fig. 5. Schenatic layout of the power supply. regulators, and controls' interface. Not all of the coil circuits are shown in the figure.

Each pair of opposing roles was provided with its own series water cooling cireni: - yielding a total of four parallel circuits originating from the angnet-mounted supply and return manifolds. The coils were kept as distant from the aperture of the magnet as practical as shown in Figs. 1 and 6 . Each coil consists of 10 turns of $0.555-\mathrm{cm}-0 . \mathrm{d} ., 0.318-\mathrm{cm}-$ i.d. OFitC copper tube. This tubing was wound to approximate form and then sheathed with fiberglass tubing after winding and frior to potting. Shell Epon 815 epoxy filled with 900 mesh aluminum oxide (using Shell Diethanolamine hardener for radiation resistance) was used to pot the coils. Each coil was then vacuum filled and cured to $70^{\circ} \mathrm{C}$ overnight.

The circular yoke was fabricated fron comercially available SAE C1015 steel tubing, stress relieved before machining. It has a bore of $16.6 \mathrm{~cm}$ with $26.6-\mathrm{cm} 0 . \mathrm{d}$, and $22-\mathrm{cm}$ length. To allow accurate positioning of the poles, slots were cut in the yoke with a vertical horing mill. Pairs of opposing poles were individually installed with an ail lowable separation error of $22 r_{a} \times 10^{-3}$, or le's.

The magnet bujlt to these specifications is rated for 2500 At/pole with a voltage drop of 1.75 V/pole. Each pole has a 10 full turns with a mean length per turn of $248 \mathrm{~cm}$. Coil power is calculated to be $430 \mathrm{~W} /$ pole at $250 \mathrm{~A}$. Water flow per circuit is $2.2 \mathrm{\ell} / \mathrm{min}$ with a $14-\mathrm{kg} / \mathrm{cm}^{2}$ pressure drop through the coils. With a total flow of $9 \mathrm{l} / \mathrm{min}$ through four parallel circuits, coil water velocity is calculated at $30 \mathrm{~cm} / \mathrm{s}$ and $\Delta T$ is calculated to be $5^{\circ} \mathrm{C}$.

1t should be emphasized that this system was designed with certain specific needs in mind, mainly to provide a reasonibly large dipole field integral 


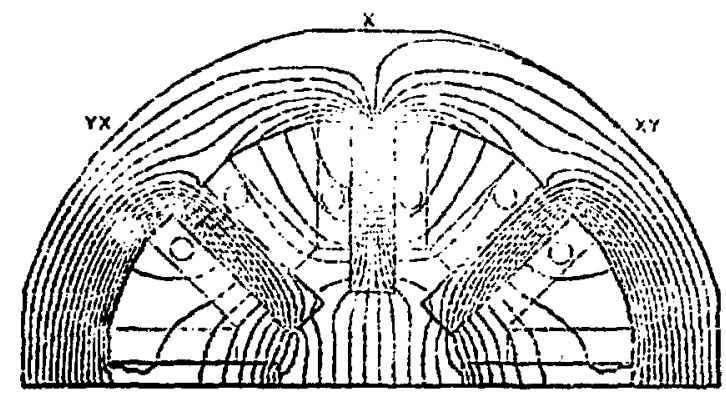

Fig. 6. Basic geometry of half of agnet used in POISSON calculations, with predicted ficld distribution when the coils containing circles are excited to give a dipole distribution in the horizontal plane.

with good uniformity in a location with significant restrictions on the physical length. The versatility of the magnet is clearly enhanced by its small overall size (it accupies only a $40-\mathrm{cm}-0 . \mathrm{d}$. by $29-\mathrm{cm}-$ long volue), its light weight $(\approx 70 \mathrm{~kg})$, its unique bussing arrangement, and its comparatively high fields. Furtherwore, the use of comonly stocked itees resulted in the use of less than 100 man-h of anchine shop time for this design. One obvious modification in the present design would be the use of tape-wound coils, which would simplify the cooling and thereby reduce both size and cost as well as considerably simplify its use in some applications.

Before discussing the magnetic measurements which verify the conclusions of Sec. I1, a word is in order about the practicality of such a system. To some extent, the verdict. depends on the application and the control instruinentation available. For those cases where one requites either a dipole or quadrupole configuration with an arbitrary field orientation, the controls ian be arranged exactly the same as for conventionil magnets of these types, i.e., one- or two-knob sysiems. However, for multipurpose operation, it is simpler and more efficient to interface the current cintrols through a computer which "interprets" knobs assignable as dipole, quadrupole, and octupole. Ir iny system which already uses computers to set magnets, this should entail nothing more than some additional software and the control hardware.

In all of the measurenents discussed in the next section, the currents were set remotely and monitored with the LAMPF control computer. For instance, besides autonatically setting various stored dipole, quadrupole, and octupole solutions with different cycling procedures, the three currents $I_{x y}=J(1,-3), I_{x}=J(2,-2)$ (or $\left.I_{y}\right)$, and $I_{y x}=$ $I(3,-1)$ - required to provide a dipole field in the $y$ (or $x$ ) direction, were set simultaneously with the computer by assigning a single "tweek" knob at the computer console in very wuch the sane way one would manual Iy vary the current of a conventional dipole maynet. This particular mode has been used for more than two years for the two steering magnets used in the LAMPF switchyard.

\section{OCTUPOLE PERFORMANCE AND CAPABILITIES}

In searching for a high-field and high-fielduniformity steering magnet for experimental ray tracing, ${ }^{3}$ a number of different geometries and types of magnets were considered. As discussed above, the most versatile system has a 12-pole geometry, whereas the most practical one is the 8-pole magnet. For our purposes, both of these systems have the attractive feature of providing corrections for rotational misalignments of quadrupole twister units. They hoth have many other uses, and in this section we discuss a rumber of measurements that were made to verify that such magnets can actually be made to work essentially as predicted in Sec. II.

The overall design of the octupole described in Sec. 111 was based on a rather complete computer simulation of the system which assuned finite permeability and two-dimensional fields. These calculations were done with the code POIsson" for the geometry shown in Fig. 6. The only symetry assumed in the calculations was midplane symetry, so that we were able to make certain checks on the calculations. In addition, a number of other geometries were studied with this code and some of the results, which are representative of each basic type of magnet, have been included as a comparison to the octupole performance. In the discussion below, we consider each excitation mode of the octupole separate1y. We emphasize that 911 of the comparisons to theory which are given is the figures below come from the two-dimensional PU:SSON calculations.

"POISSON is an improved version of TRIM and was developed by J. R. Spoerl, R. F. Holsinger, and Klaus Halbach. 


\section{k. Dipole Excitation}

Some of the basic dipole types studied during this investigation are shown in Figs. 7 and 8 . Figure 7 a shows the conventional window-frame geometry which was evaluated, and Fig. $7 \mathrm{~b}$ shows a variant of that design which converts easily into the basic $H$ cype geometry of Fig. 8. A variant of the H-type geometry which has some similarity with the final octupole design is shown in Fig. 8b. Figures 6-8 were all produced with POISSON and show the magnetic field lines throughout the magnet in each case.

Figure 9 shows the predicted distributions in the median plane, plotted as percentage deviation versus the distance from the center, in units of the available half-aperture. The required excitation (ampere-turns) to produce the same field $B_{0}$ at the center of the magnet was used in each case. The solid line in the upper quadrants gives the results for the window-frame geometry. Although this design provides a reasonable field uniformity, its major shortcoming is the magnitude of the field which is obtainable-particularly for a double-field system, i.e., when it is required to supply both $B_{x}$ and $B_{y}$ with the same magnet. If one tries to improve on this particular aspect by going to a double l1-type

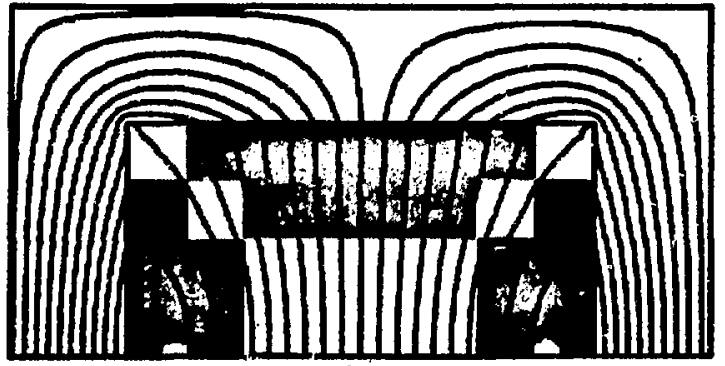

w

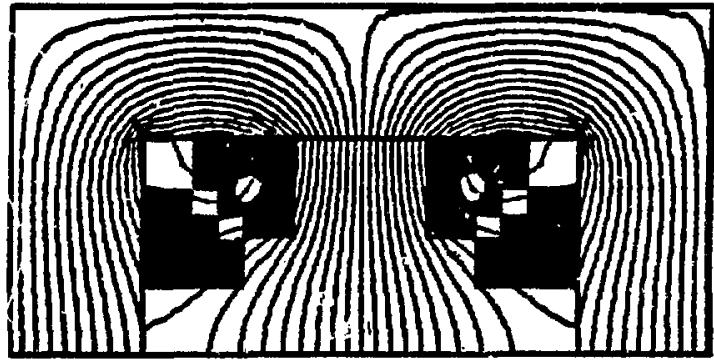

(1)

Fig. 7. Basic geometry of half the window-frane geometry calculated with POISSON. Figure 7a shows the conventional coil configuration and Fig. $7 b$, a variant, converts easily into H-type. design, one gets results that are generally bracketed by the solid and dashed curves shown in the lower quadrants. While the absolute field level increses

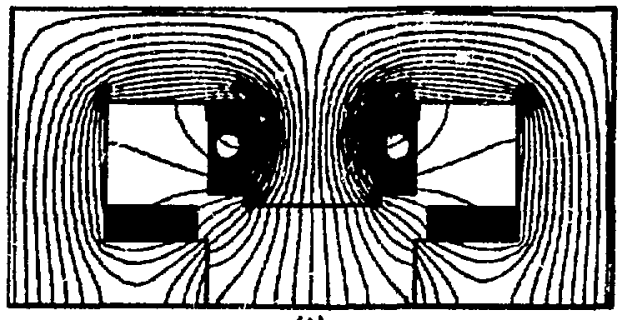

(A)

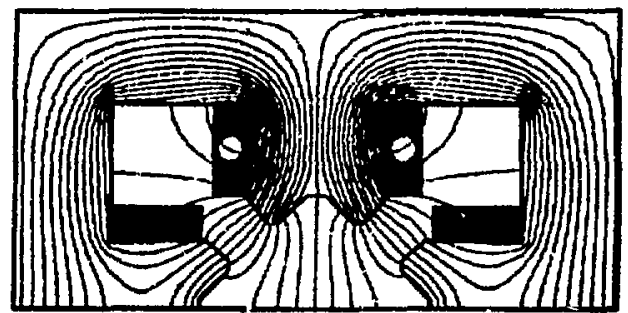

(0)

Fig. 8. Basic geometry of half the H-type geometry calculated with POISSON. Figure 8a shows what could be called a conventional geonetry and Fig. $8 \mathrm{~b}$ is an attempted design mprovement.

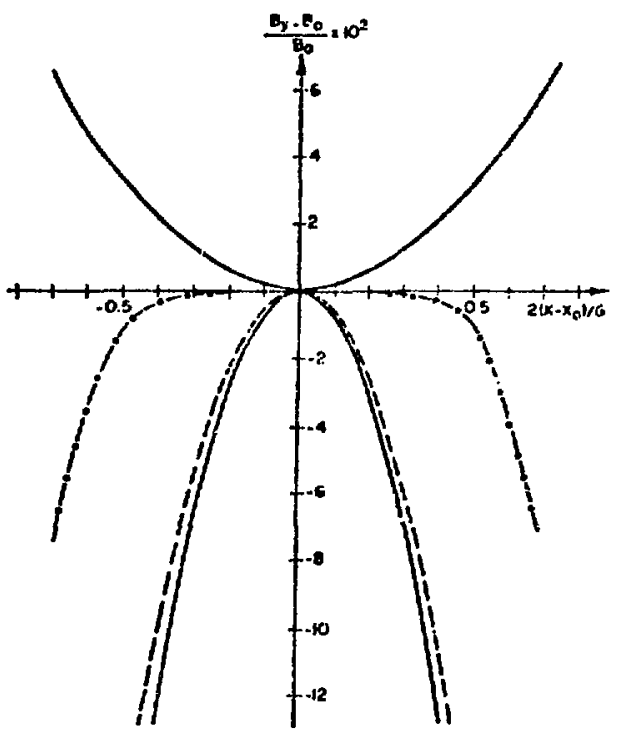

Fig. 9. Results of poIsSON calculations for different types and geometries of dipole magnets. Upper curve shows percentage deviation from uniformity across the gap of conventional window-frame design; lower curves show results for H-types and octupole design described in text. 
for a given number of ampere-turns, the ficld unjformity decreases drastically. The solid line here represents a conventional syuare pole whereas the fushed line is intended to show the futility of varying this hasic pole contour to improve field uniformity. This san be understood by not ing that the pole width must generally be less than the gap height in the symmetric double ll-desigu.

Finally, the dot-dashed 1 ine shows the predicted results for the 8 -pole system. The field uniformity calculated for poles with square contours (fig. 6) is $<+10^{-4}$ over the cent ral quarter-aperture. Furthermore, in contrast to the window-frame design, the induction field obtainable for a given nuber of ampere-turns per pole is comparible to the IItype design.

Figure 10 gives tha results of the inzegral field measurements on the b-pole mognet when excited acending to the prescriptions of Sec. It. The upper and lower curves compare the results of a $: 5 \%$ sxcitation error from the prescribed setting in the sccondiry cuerents $1_{x y}$ and $I_{y x}$. In the case

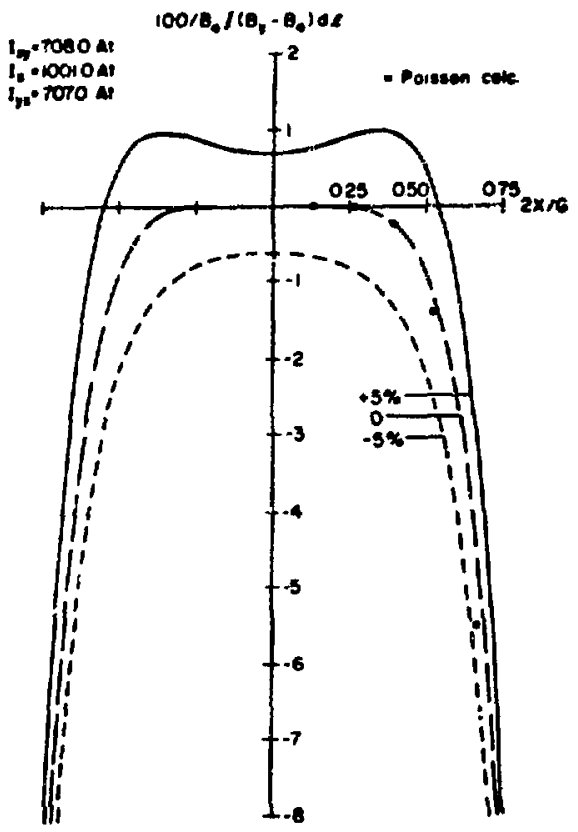

Fig. 10. Results of integral ficld measurements of magnet shown in Figs. 3 and 4 when operated in the dipole mode compured to central field predictions of POISSON. of the positive current overvalues for $I_{x y}$ and $I_{y x}$ ' the field uniformity was $\$ 10.25 \%$ over half the aperture, which is still better than is ohtained with most conventional dipole design geometrirs used for spectrometers. The dots in the figure are the prodicted values from Fig. 9. The measured curve is somewhat hetter than predicted, certainly better than one part in $10^{4}$ over the central quaster of the magnet.

To see how the previous excitation history of the magnet affects the ficld distribution, the measurements of Table II were made. This table gives the normalized, fractional gap width $(\delta x / G)$ over which the field integral is constant to the specified pereentage. The first row (Co1s. 1-3) shows the width over which the total field variation is $<0.01 \%$ due to hringing the currents directly from zero to their final values (1) with no overshoot (10.0). (2) with a 50\% overshont (0.5), and (3) a $100 \%$ overshoot $(1,0)$. The last two colunns of the first row give the results for a $100 \%$ uvershoot in the cases when there is $5 \%$ excess current in the two secondary coils ( $I_{x y}$ and $I_{y x}$ ) and when the measurements are made above the median plane $(y=0)$ by an amount $y / c=0.12$. Irom these data, it is clearly better to set the dipole fields by approaching the final value from ahove in applinations where extended field uniformity is important, even though at no time during the cycling should the fields be $>10 \mathrm{kr}$ anywhere in the iron of the poles or yoke.

A related effect is the degree to thich linear superposition applies in this kird of magnet hecause

TABLE II

FRACTIONAI. CURRENT OUERSHDOT

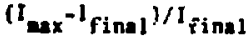

\begin{tabular}{|c|c|c|c|c|c|}
\hline & 0.0 & 0.5 & 1.0 & $1 . n^{x}$ & $1.0^{b}$ \\
\hline 0.01 & 0.11 & 0.21 & 0.26 & 0.08 & 0.16 \\
\hline 0.05 & 0.23 & 0.29 & 0.31 & 0.11 & 0.19 \\
\hline 0.10 & 0.29 & 0.33 & 0.34 & 0.16 & 0.22 \\
\hline 0.50 & 0.41 & 0.43 & 0.44 & 0.18 & 0.35 \\
\hline 1.8 & 0.47 & 0.49 & 0.49 & $0 . .52$ & 0.43 \\
\hline 5.0 & 0.64 & 0.65 & 0.65 & 0.66 & 20.75 \\
\hline
\end{tabular}
'Current in secondary coils ( $I_{x y}$ and $t_{y x}$ ) at 5 :

beasurements above median plane $(y=0)$ by an amount $y / G=0 .: 2$. 
this essentially determines how versatile and how easy it will be to operate. Figure 11 shows the results of measuring magnetization curves for three different spatial orientations of the resultant dipole field vector. The line in the figure is a straight line drawn through the boxes representing the data for a field at $45^{\circ}$ to the other two. The magnet is linear over the full range from 0 to $25 \mathrm{kc}-\mathrm{cm}$.

\section{B. Quadrupole Excitation}

Figure 12 shows the results of exciting the magnet as a conventional quadrupole, i.e., of exciting every other pole centered at $45^{\circ}$ to the horizontal and vertical axes. The plot gives the actual quadrupole field across the $x$-axis using the sane integral coil as used for the dipole measurements of Figs. 10 and 11 . The straight line with constant slope was urawn to show the degree of deviation from a constant gradient' field and the dots are again the POISSON predictions for the square pole contour. The gradient is constant to better than one purt in $10^{3}$ over the central quarter. aperture. Although the system dous not provide a good quadrupole field in the vicinity of the bore

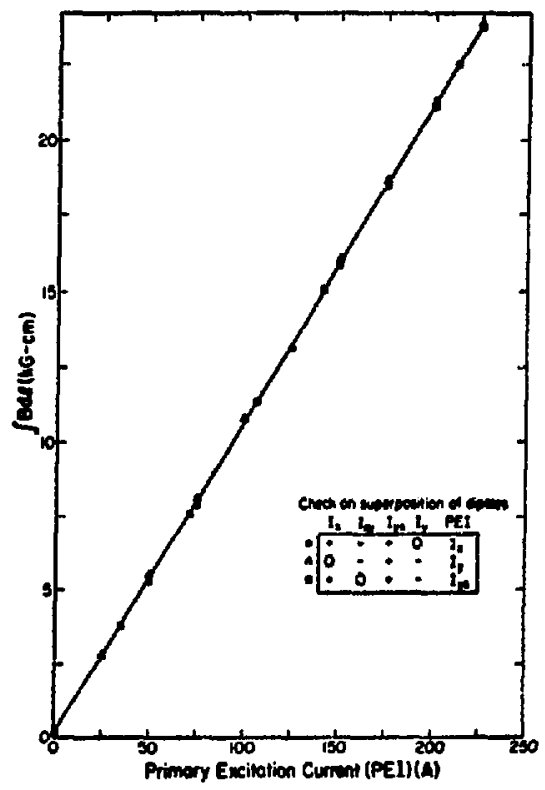

Fig. 11. Results of integral field measurements showing superposition of dipole fields. Solid line is a straight line through measured values when field is at $45^{\circ}$ to vertical and horizontal fields.

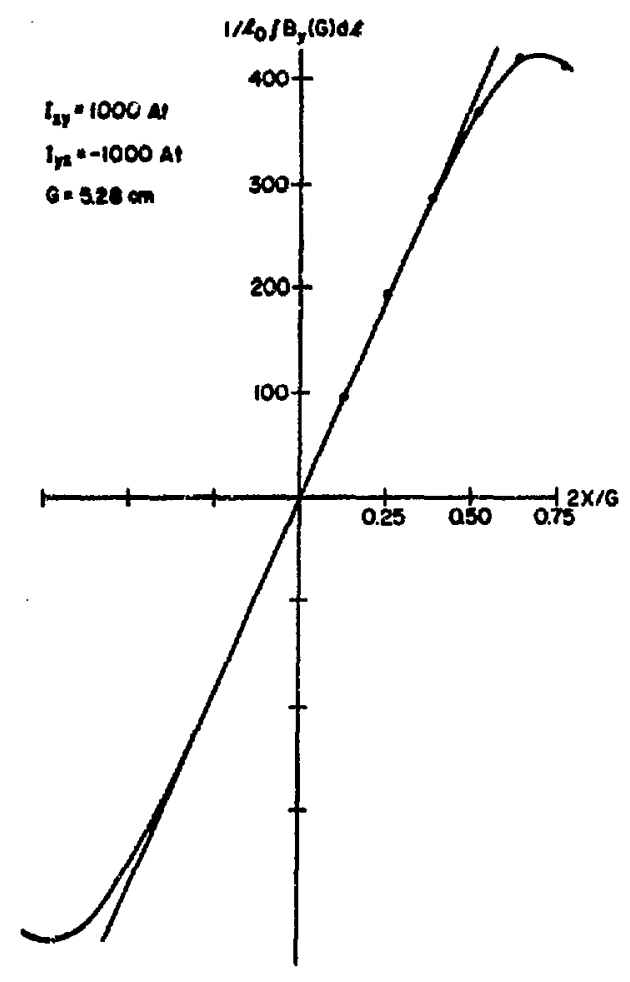

Fig. 12. Results of integral field measurements of magnet shown in Figs. 3 and 4 when operated in quadrupole node with central field predictions of POISSON.

radius, it is significant how close the measurements cone to the predictions.

The integral harmonic content of this excjtation pattern was also measured and is given in Table III in percent of the $n \times 2$ component extrapolated to the bore radius. The range of variation of the different multipoles with excitation current was negligible, varying generally by less than $\pm 0.02^{\circ}$ of the quadrupole component over the full range of current variation which was measured (50-200 A). As expected from the discussion in Sec. II, the largest contributions come from the $n=6$, duodecapole term. Although this term dominates, others which might have been expected to he zero hecause of symmetry arc still surprisingly large, possibly owing to synmetry violations in the assembly even though assembly was rather carefully controlled. 
TABLE III

INTEGRAL HARMONIC CONTENT OF QUADRUPOLE AND OCTUPOLE EXCITATION PATTEKNS FOR 5,28- Cm BORE

\begin{tabular}{crc}
$n$ & $\begin{array}{c}\text { Quadrupole } \\
\text { (Percent of } n=2)\end{array}$ & $\begin{array}{c}\text { Octupole } \\
\text { (Percent of } n=4)\end{array}$ \\
\cline { 2 - 3 } 2 & 100.00 & 0.31 \\
3 & 0.18 & 0.34 \\
4 & 0.31 & 100.00 \\
5 & 0.60 & 0.32 \\
6 & 105.90 & 0.23 \\
7 & 1.37 & 0.46 \\
8 & 1.00 & 0.62 \\
9 & 1.24 & 0.86 \\
10 & 11.20 & 1.00 \\
12 & 2.11 & 8.36 \\
14 & 29.30 & 1.55 \\
16 & 3.20 & 3.16 \\
\hline
\end{tabular}

Figure 13 shows the results of exciting the magnet in different fatterns to check whether linear superposition applies, i.e., whether one can easily rotate the quadrupole field distribution as in Fig. 11 for the dipole excitation. The plot was obtained by setting the various currents according to the proper prescription and then measuring the integral. This was done for a range of currents. Again, the solid line is a straight line through the $22.5^{\circ}$ rotated field.

\section{Octupole Excitation}

When all currents werc excited with equal magnitudes and alternating signs to produce an octupole distribution, we obtained the results given in the third column of Table III. The numbers are the integral field harmonic contents, expressed in percent of $n=4$ at the bore radius. The first allowed harmonic above $n=4$ is $n=12$, which is the largest contribution even though this term would be zero for the ideal contour. From the numbers in Table III, this system would apprar to be an acceptably good octupole over the central half of the aperture although no attempt was made to improve it either hefore or after fabrication except as discussed in Sec. III.

\section{DISCUSSION}

We have shown that general-purpose, multipole magnets are possible that have very specifje advantages and which are inexpensive and easy to use. In the case of the octupole geomerry, it is easy to build magnets which provide wltipoles or linear combinations of multipoles, oriented at any angle about the bean, that are accurate to better than $\pm 0.5 \%$ over half the aperture.

There are many possible applications where such magnets would be useful, and they have been used at LAMPF in three quite different ways. Singly, they have been used as high-field steering magnets and as genera1-purpose quadrupoles to correct angular misalignments of a beam rotator system. In pairs, they have been used in conjunction with a zero-phase space beam to create any combination of $x, \theta, y, \phi$ (and $\delta$ ) phase space points for experimental ray tracing.

A single octupole, serving as a quadrupole (Q) in a quadrupole-dipole (QD) or QDD spectrometer system could be used in the conventional way or to correct effects such as kinematic line-broadening 4 associated with the finitc acceptance angles in the scattering plane. In multiples, they could be used in periodic accelerating structures or high-resolution

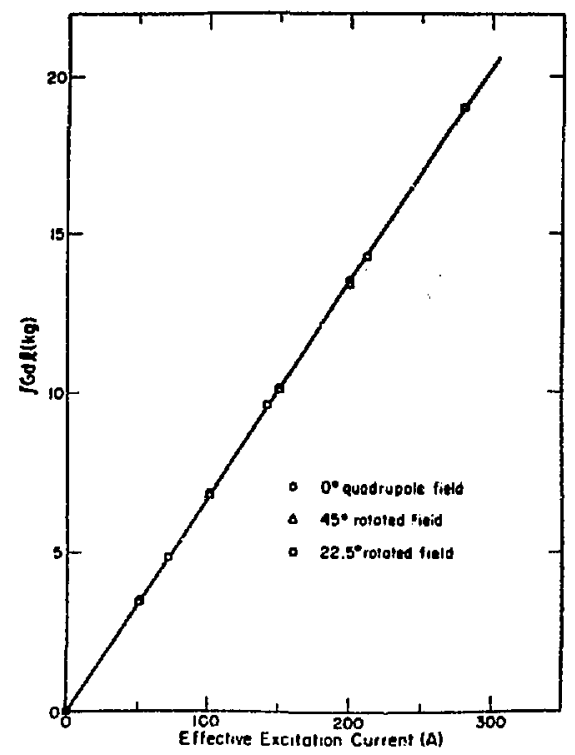

lig. 13. Results of integral field measurements showing superposition of quadrupole fields. Solid line is a straight line through measured values when the quadrupole field is rotated at $22.5^{\circ}$, intermediate between measurements for field orientations of $0^{\circ}$ and $45^{\circ}$. 
beam lines. These applications are all valid, but wo believe these systens could prove useful for any application requiring one or more of the following characteristics.

- Unique, high-field uniformity of the dipole excitation.

- Snall size of the magnets, for the field integrals which are provided.

- Ability to superimpose independently variable, aultipole fields within the same magnetic volume rather than disperse them serially along a system.

- The ability to orient these fields at any angle about the axis of the magnet.

A comment is necessary concerning the overall cost of such a systen - including its power snpply and controls. As already discussed, it is possible to run several octupoles on a single unregulated power supply (bipolar). This results in a compact system which is easy and inexpersive to control. Furthermore, and perhaps of more importance, it is simple to use. Even if one does not have a computer available, it is possible to have a system which functions essentially the same way as the one described, using microprocessors which can easily and inexpensively handle all of the logical operations needed to run the octupole or duodecapole.

Finally, this prototype correction element has functioned well enough that two of the authors (KH and JES) have applied for a patent on these types of systems.

\section{ACKNOWLEDGMENTS}

While a number of people contributed to the physical realization of the octupole, we especially thank Jack Busse for his design/detail work, Edgar Bush for the coil fabrication, Jesse Lee for the machine shop work, Vern Rogers for the control instrumentation, John Sharp for the design and checkout of the regulators and Nancy Spencer for the various computer control software. We also thank Ann Aldridge, Alexander Harvey, and Maynard Roberts for help with the various aspects of the magnet measurements.

\section{REFERENCES}

1. R. Benaroya and W. J. Ramler, "Deflertion Coil for an External Accelerator Beam," Nucl. Instrum. Methods 10, 113-120 (1961).

2. K. Halbach, "First Order Perturbation Effects in Iron-Dominated Two-Dimensional Symmetrical Multipoles," Nucl. Instrum. Methods 74, 147-164 (1969).

3. J. E. Spencer and H. A. Thiessen, "Some High Resolution Teahniques for Use with Negative Ion Beams," in Proceedings of the 1972 Proton Linear Accelerator Conference, Los Alamos Scientific Laboratory report LA-5115 (1972), pp. 415-421.

4. D. L. Smith and H. A. Enge, "A High-Resolution, Charged Particle Spectrometer with Doppler Correction," Nuc1. Instrum. Methods 51, 169-171 (1967). 